\title{
Green Degree Comprehensive Evaluation of Elevator Based on Fuzzy Analytic Hierarchy Process
}

\author{
Lizhen $^{1}$,zhangruijun ${ }^{2}$ and WangChen ${ }^{3}$ \\ ${ }^{1}$ Lizhen,graduate student, College of mechanical and electrical engineering ,Shandong JianZhu University.Jinan 250101, China. \\ ${ }^{2}$ Zhangruijun, Professor, College of mechanical and electrical engineering, Shandong Jianzhu University.Jinan 250101, china. \\ ${ }^{3}$ WangChen, graduate student, College of mechanical and electrical engineering ,Shandong JianZhu University, Jinan 250101, China.
}

\begin{abstract}
The green design of the elevator has many characteristics which contains many factors and the combination of qualitative and quantitative. In view of the fuzzy problem of evaluation index information, fuzzy analytic hierarchy process and fuzzy comprehensive evaluation model are combined to evaluate the green degree of elevator. In this method, the weights of the indexes are calculated by using the fuzzy analytic hierarchy process and the fuzzy analytic hierarchy process is used to calculate the weights of each level. The feasibility will be defined of using green degree evaluation of elevator system as an example to verify the method.
\end{abstract}

Keywords: Fuzzy analytic hierarchy process; elevator; Index system; Green Degree;

\section{Introduction}

With the continuous development of society, the research of green design has become a new focus of green manufacturing. Product design is the key to realize product design innovation, the green degree is the key to measure the green design of the scheme. Green degree is an important index for the evaluation of products, and it is the quantitative value of the product "green degree". Elevator's green degree is in the economic, technological, environmental and other three aspects of the evaluation of the elevator, but also a comprehensive evaluation of the whole life cycle. The weight of the index has an important influence on the evaluation of the whole scheme. The fuzzy analytic hierarchy process can be used to solve the problem of the weight of green design index. Fuzzy comprehensive evaluation model of the fuzzy hierarchy analysis to each index with specific processing method to realize the qualitative index into quantitative indicators, the comprehensive evaluation of all levels of the indicators was carried out by the comprehensive evaluation criteria and normalized treatment. Is characteristic of fuzzy comprehensive evaluation model of each layer comprehensive evaluation and on the evaluation of outcomes, interlocking, achieve the overall fuzzy comprehensive evaluation. The fuzzy comprehensive evaluation model's is related to each layer comprehensive evaluation,which achieved the overall fuzzy comprehensive evaluation.

At present, the method of evaluating the degree of product of green degree is a method of analytic hierarchy process, expert evaluation method, new method of evaluation and so on. The evaluation of green degree of industrial products and their parts by using the analytic hierar-

Corresponding author:

Lizhen,1073991041@qq.com. chy process from the famous scholar ying ${ }^{[1]}$. Wang Yue $\mathrm{jin}^{[2]}$ uses the multi-level fuzzy comprehensive evaluation method to solve the problem of the product in the whole life cycle. These methods have done some research on the evaluation of product green degree. However, the evaluation of the index weight is still dominated by the human, and the structure of the judgment matrix is lack of flexibility.

In this paper, the fuzzy analytic hierarchy process is used to calculate the weights of the indexes, and the subjectivity of the analytic hierarchy process is overcome. First, we construct the evaluation index system of green elevator traction system; then, through the triangle ambiguity function of indicator of pairwise comparison judgment matrix, using fuzzy AHP analysis method to calculate the weight of each index, to achieve the qualitative indexes into quantitative. Finally, based on the fuzzy analytic hierarchy process (AHP) to establish the elevator green degree fuzzy comprehensive evaluation model and the example is analyzed, the system that the green degree of value.

\section{The establishment of evaluation index sys- tem of the elevator traction system}

The elevator traction system is the power equipment of the elevator, the elevator is also called the host, occupy an important position in the whole system of elevator. The traction system of green degree evaluation is a comprehensive evaluation of the evaluation index from three 
aspects of economy, technology, environment. Build index system as shown in Fig. 1.

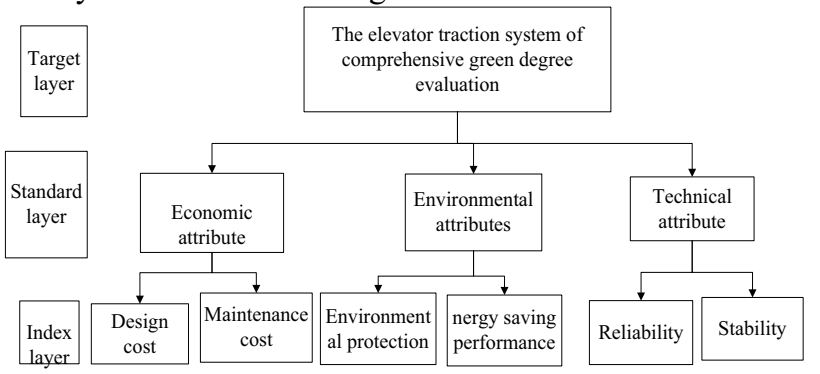

Fig.1 Elevator traction system

\section{Fuzzy comprehensive evaluation method of the elevator traction system model based on AHP}

\subsection{Triangular fuzzy judgment matrix}

In fuzzy mathematics, the triangular fuzzy function is used to express the weight. Firstly, through the index two, the judgment matrix is obtained, and the number of EI in the matrix is expressed as important, SMI is important, VSMI is very important, AMI is absolutely important. The digital measurement scale is shown in fig. 2 .

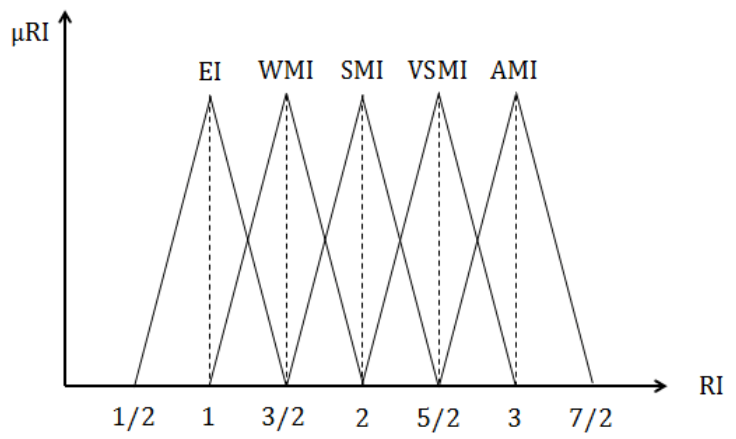

Fig.2 The relative importance of the language scale

\subsection{Comprehensive evaluation criteria for the evaluation of the comprehensive value}

In order to $a_{i j}$ express an important degree value of an important degree value of $i$ index in fuzzy judgment matrix relative to the $j$ index index in fuzzy judgment matrix relative to the $\mathrm{j}$ index. $D_{i}^{k}$ can be calculated by formula 1

$$
D_{i}^{k}=\sum_{j=1}^{n} a_{i j}^{k} /\left(\sum_{i=1}^{n} \sum_{j=1}^{n} a_{i j}^{k}\right) \quad i=1,2, \ldots . n
$$

\subsection{Normalized weight value of the evaluation criteria}

Let $M_{1}=\left(l_{1}, m_{1}, u_{1}\right)$ and $M_{2}=\left(l_{2}, m_{2}, u_{2}\right)$ be two triangular fuzzy numbers. $V\left(M_{1}>M_{2}\right)$ express when
$M_{1}>M_{2}$ the possibility of a triangular fuzzy number,so

$$
\begin{aligned}
& d^{\prime}\left(c_{1}\right) V\left(M>M_{1} M_{2} \ldots . M_{K}\right) \\
& =\min V\left(M \geq M_{i}\right) \quad(i=1,2, \ldots k)
\end{aligned}
$$

Weight calculation, if $M_{1}>M_{2}$ the possibility of triangular fuzzy functioncan be defined

$$
\begin{gathered}
V\left(M_{1} \geq M_{2}\right) \\
=\sup _{x \geq y}\left[\min \left(u_{m 1}(x), u_{m 2}(y)\right]\right. \\
V\left(M_{1} \geq M_{2}\right)=u(d) \\
=\left\{\begin{array}{cc}
1 & m_{1} \geq m_{2} \\
\frac{l_{2}-u_{1}}{\left(m_{1}-u_{1}\right)-\left(m_{2}-l_{2}\right)} & m_{1} \leq m_{2}, u_{1} \geq l_{2} \\
0 & \text { otherwise }
\end{array}\right.
\end{gathered}
$$

The weight vector of all the criteria is calculated:

$$
W=\left[d^{\prime}\left(c_{1}\right), d^{\prime}\left(c_{2}\right), \ldots \ldots . d^{\prime}\left(c_{n}\right)\right]^{\mathrm{T}}
$$

Standard treatment can be the final weight:

$$
W^{\prime}=\left[d\left(c_{1}\right), d\left(c_{2}\right), \ldots \ldots d\left(c_{n}\right)\right]^{\mathrm{T}}
$$

\subsection{Multilevel fuzzy comprehensive evaluation}

Regard $\left(U_{i 1}, U_{i 2}, \ldots U_{i n}\right)$ as the first level indicator, The evaluation set is $V=\left(V_{1}, V_{2}, \ldots V_{n}\right)$, the corresponding weight is $W=\left(W_{1}, W_{2}, \ldots W_{n}\right)$.In the first level indicators, the corresponding two level indicators have many numbers. Factor set is $\left(U_{i 1}, U_{i 2}, \ldots U_{i n}\right)$.The corresponding weight is $W^{\prime}=\left(W_{i 1}, W_{i 2}, \ldots W_{i n}\right)$. Each index of the evaluation matrix is $R_{i}$.

1) The one level fuzzy comprehensive evaluation is $B_{i}=W_{i} \times R_{i}$, calculation results need to be normalized.

2) Two stage fuzzy comprehensive evaluation. The results of using a fuzzy comprehensive evaluation multiplied each factor matrix,so $B_{i}^{\prime}=B_{i} \times R_{i}$, calculation results need to be normalized.

\subsection{Evaluation of product green degree}

In the first stage fuzzy comprehensive evaluation and the two level fuzzy comprehensive evaluation, the weight value of the product evaluation index and the comprehensive evaluation are worth the. According to the relevant provisions of the relevant provisions of the degree of green product and expert judgment in which the comprehensive evaluation of the green degree of the indicators is

$$
G=V \times 100
$$

The value of green degree of 60 points to determine the product is green design. 


\section{Case analyse}

\subsection{Determination evaluation of green degree}

In order to facilitate the comprehensive evaluation of the various indicators, according to the relevant provisions of the relevant provisions of the five level method is used to establish the evaluation set is $V=\left(V_{1}, V_{2}, V_{3}, V_{4}, V_{5}\right)$, As shown in Table 1, the comprehensive evaluation of the green degree of the indicators at all levels is:

Table 1 weight value and standard value of green degree

\begin{tabular}{cccccc}
\hline $\begin{array}{c}\text { Evalua- } \\
\text { tion } \\
\text { grade }\end{array}$ & Better & Good & $\begin{array}{c}\text { Gen- } \\
\text { eral }\end{array}$ & Bad & Worse \\
\hline $\begin{array}{c}\text { Weighte } \\
\text { d value }\end{array}$ & 1.0 & 0.8 & 0.6 & 0.4 & 0.2 \\
$\begin{array}{c}\text { Stand- } \\
\text { ard } \\
\text { score }\end{array}$ & $1 \sim 0.9$ & $0.9 \sim 0.7$ & $0.7 \sim 0.5$ & $0.5 \sim 0.3$ & $0.3 \sim 0.1$ \\
\hline
\end{tabular}

\subsection{Structural factor set}

Product green degree evaluation should reflect products in all aspects of green, comprehensive of the comprehensive evaluation of "green" in the design of elevator traction system the green degree of the pursuit of environmental impact minimization, resource utilization rate is highest, and the economic benefit is high, the maintenance cost is low. So this paper summarizes the three factors in the construction of the factor set, namely, the factor set is:

$$
\begin{aligned}
U= & \left\{u_{1}, u_{2}, u_{3}\right\} \\
= & (\text { Economic attribute }, \\
& \text { Environmental attributes, } \\
& \text { Technical attribute })
\end{aligned}
$$

\subsection{Calculate the weight of the first class index and the weight of the two index}

According to the index of two two, the fuzzy judgment matrix is obtained, as shown in Table 2.

Table 2 fuzzy judgment matrix B

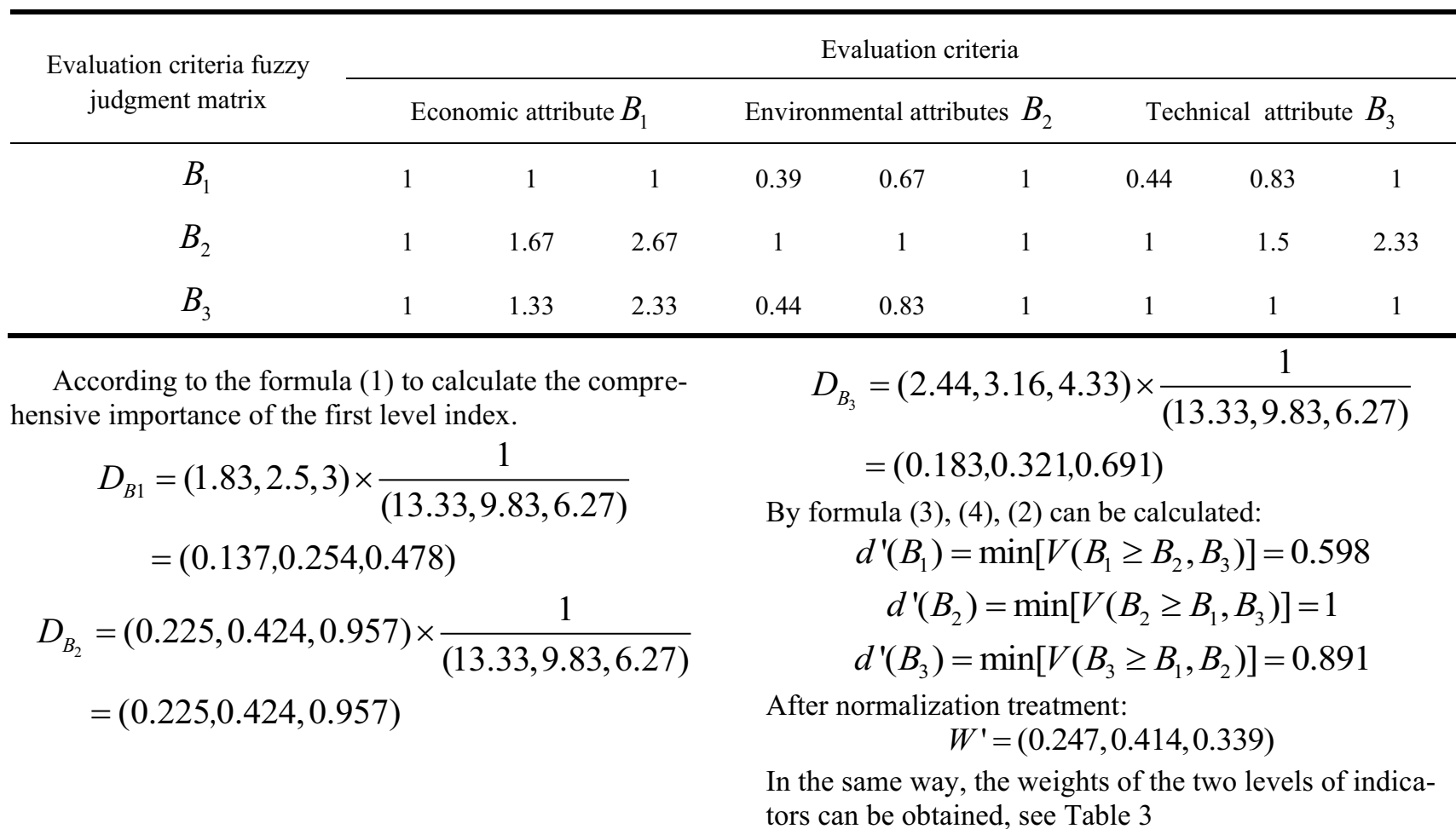


Table 3 The weight of the comprehensive evaluation index system and fuzzy elevator

\begin{tabular}{|c|c|c|c|c|c|c|c|c|}
\hline \multirow{2}{*}{$\begin{array}{l}\text { First level } \\
\text { indicator }\end{array}$} & \multirow{2}{*}{ Weight } & \multirow{2}{*}{ Two stage index } & \multirow{2}{*}{ Weight } & \multicolumn{5}{|c|}{ Green degree evaluation } \\
\hline & & & & bettet & Good & General & bad & worse \\
\hline$B_{1}$ & \multirow[b]{2}{*}{0.247} & cost & 0.215 & 0.5 & 0.5 & 0.4 & 0.1 & 0.1 \\
\hline $\begin{array}{l}\text { Economic } \\
\text { indicators }\end{array}$ & & $\begin{array}{l}\text { MaintenanCe } \\
\text { cost }\end{array}$ & 0.128 & 0.5 & 0.6 & 0.4 & 0.1 & 0 \\
\hline \multirow{2}{*}{$\begin{array}{c}B_{2} \\
\text { environ- } \\
\text { mental indi- } \\
\text { cators }\end{array}$} & \multirow{2}{*}{0.414} & $\begin{array}{c}\text { Environmental } \\
\text { rotection }\end{array}$ & 0.35 & 0.6 & 0.7 & 0.5 & 0.1 & 0 \\
\hline & & $\begin{array}{l}\text { Energy saving per- } \\
\text { formance }\end{array}$ & 0.327 & 0.6 & 0.8 & 0.6 & 0.2 & 0 \\
\hline \multirow{2}{*}{$\begin{array}{c}\mathrm{B}_{3} \\
\text { Technical } \\
\text { index }\end{array}$} & \multirow{2}{*}{0.339} & $\begin{array}{l}\text { Reliabl perfor- } \\
\text { mance }\end{array}$ & 0.32 & 0.4 & 0.3 & 0.4 & 0.1 & 0.1 \\
\hline & & $\begin{array}{l}\text { Stability perfor- } \\
\text { mance }\end{array}$ & 0.24 & 0.3 & 0.4 & 0.4 & 0.2 & 0.1 \\
\hline
\end{tabular}

Fuzzy comprehensive evaluation is carried out by using the fuzzy comprehensive evaluation results of the first grade two:

$$
\begin{aligned}
B & =R \times W \\
= & (0.247,0.414,0.339) \\
& \times\left[\begin{array}{ccccc}
0.1715 & 0.1843 & 0.1372 & 0.0343 & 0.034 \\
0.4062 & 0.5066 & 0.3712 & 0.1 & 0 \\
0.2 & 0.192 & 0.224 & 0.112 & 0.056
\end{array}\right] \\
& =(0.278,0.32,0.263,0.088,0.027)
\end{aligned}
$$

According to the above results, the comprehensive evaluation results are calculated by using the weighted average method:

$$
\begin{aligned}
V= & 0.278 \times 1+0.32 \times 0.8+0.263 \times 0.6 \\
& +0.088 \times 0.4+0.027 \times 0.2 \approx 0.75
\end{aligned}
$$

According to the formula (7): if green degree greater than 60 points of design for green design,we can say this design is green design. Through calculation results can be known this design of the elevator traction system is green design and the green degree belongs to good range.

\section{Summary}

For the first time, the fuzzy analytic hierarchy process and fuzzy comprehensive evaluation method is applied to the elevator traction system of green degree evaluation and evaluation of product green degree is considered from the aspects of economy, technology and environment, to achieve twodimensional index is extended to three-dimensional index. The evaluation of the degree of green degree of the index weight is calculated by the fuzzy analytic hierarchy process. With fuzzy comprehensive evaluation method of elevator traction system, the whole life cycle of green degree evaluation, it is concluded that the value of its green degree .The method of comprehensive consideration elevator traction system factors, has strong practicability, on product design has guiding significance.

\section{References}

[1] Tian Q H, Xiao R B, Evaluation method for design scheme based on information axiom and fuzzy mathematics Journal of agricultural machinery,Vol.39(2008),p.136-140.

[2]Hurt,Kimi,YamaMotor.Measurement of green productivity and its improvement. Journal of Cleaner Production,Vol,12(2004),p. 673-683.

[3]Jonathand,Lintondea.A method for ranking the greenness of design decision.Journal of Mechanical Design, Vol,124(2002),p. 145-150.

[4]Ying B S, Zhang H, Yi J G. Research on the design and evaluation method of green product . Machine tools and hydraulic.Vol,3(2004),p.39-41.

[5]Meng Xianyi, Wang Yuejin. Research on multi level fuzzy evaluation Methodof green product. China Mechanical Engineering.Vol,11(2000),p.1016-1019. 